\title{
A sensitive chemiluminescence based immunoassay for the detection of cortisol and cortisone as stress biomarkers
}

\author{
Jwan O. Abdulsattar ${ }^{1 *}$ (D) and Gillian M. Greenway ${ }^{2}$ (D)
}

\begin{abstract}
An electrochemically based antibody immobilization was used to perform environmentally and clinically relevant immunoassays for stress hormones biomarkers (cortisol and cortisone) using chemiluminescence (CL) detection. To achieve $\mathrm{CL}$ detection, the ferrocene tag on the antibodies was first oxidised, and this then acted as a catalyst for the luminol and hydrogen peroxide $\mathrm{CL}$ reaction. The conditions were optimised and measurements were made with an incubation time of $30 \mathrm{~min}$. Using this approach limits of detection were obtained of $0.47 \mathrm{pg} \mathrm{ml}^{-1}$ and 0.34 $\mathrm{pg} \mathrm{ml}^{-1}$ also $R^{2} 0.9912$ and 0.9902 for cortisol and cortisone respectively with a linear concentration from 0 to 50 $\mathrm{ng} \mathrm{ml}^{-1}$. The method was then applied to Zebrafish whole body and artificial saliva samples. For the Zebrafish sample recoveries of $91.0 \%$ and $90.0 \%$ were obtained with samples spiked with cortisol and cortisone, for artificial saliva the recoveries were $92.59 \%$ and $90.73 \%$ respectively. Interference studies showed only minor effects on the measurement of the analyte. A comparison between this procedure and the standard enzyme-linked immunosorbent assay (ELISA) procedure gave approximately the same $R^{2}$ values.
\end{abstract}

Keywords: Stress hormones, Biosensors, Immunoassays, Chemiluminescence

\section{Introduction}

In this study, the biomarkers of interest are stress hormones, including cortisol and cortisone that belongs to glucocorticoids (GCs) family, which are secreted depending on environmental and behavioral triggers, and follow a circadian rhythm (all day cycle) (CorbalánTutau et al. 2014). The relationship between cortisol levels and chronic stress is detected as cortisol aim is to transfer cellular processes from metabolic functions to functions that are necessary for immediate survival (i.e., in the "fight or flight" response). However, the long-term elevation of GCs starves some tissues of necessary resources and inhibits immune action, increasing the tendency to disease (Protopopova 2016; Zainol Abidin et al. 2017). For healthcare monitoring which can be used for understanding human day-night stress hormones cycle secretion, simple low-cost measurement systems are

\footnotetext{
* Correspondence: jwan.abdulsattar@uomustansiriyah.edu.iq ${ }^{1}$ Department of Chemistry, College of Science, Mustansiriyah University, Baghdad, Iraq

Full list of author information is available at the end of the article
}

needed. Environmental applications would include the effect of pollutants on fish (Kaushik et al. 2014).

Various approaches have been taken to determine stress hormones in biological samples. However, these methods either require sophisticated equipment or involves procedures with rigorous control of the experimental conditions (Oßwald et al. 2019; Luo et al. 2019; Sturmer et al. 2018; Miller et al. 2013; Del Corral et al. 2016; Gatti et al. 2009; Yeh et al. 2013; Barcellos et al. 2007; IZAWA et al. 2015; Ashley et al. 2011; Weltring et al. 2012; Russell et al. 2014; Ammann et al. 2014; Erickson et al. 2012; Kartsova and Strel'nikova 2007; Gao et al. 2015; Ceccato et al. 2014; Saracino et al. 2014; Sánchez-guijo et al. 2014; Yeh et al. 2015). Chemiluminescence (CL) is widely used for analytical measurements due to its simplicity, sensitivity and low-cost optical requirements (Adcock et al. 2019; Smith et al. 2019). The $\mathrm{CL}$ reaction of luminol with hydrogen peroxide system is frequently utilised with catalysts which include either enzymes such as horseradish peroxidase (Liu and Zhang 2015) or metal catalysts such as ferrocenecarboxaldehyde (Luo et al. 2012) that contain iron. 
The CL reaction used in this work is based a previous method described by Wright et al. for the determination of pregnancy hormones (Wright et al. 2018) in which firstly the antibody was electrochemically immobilised on to an ITO electrode, a method which was found to provide reproducible and reliable results. Secondly, the oxidised form of the redox tag (ferricenium) on the antibody acts as the heterogeneous catalyst for the chemiluminescent reaction between hydrogen peroxide and luminol.

The objective of the research presented in this paper was to provide simple, low cost and quantitative measurement system for the determination of stress hormones that was both selective and sensitive. The method was applied to Zebrafish samples and artificial saliva samples.

\section{Experimental section}

\section{Materials and methods}

Anti-cortisol antibody, anti-cortisone antibody and cortisol (hydrocortisone) were purchased from Abcam biochemicals, UK. Cortisone, phosphate buffer saline tablet (PBS), ferrocenecarboxylaldehyde (FcCHO), potassium carbonate $\left(\mathrm{K}_{2} \mathrm{CO}_{3}\right)$, sodium borohydride $(\mathrm{NaBH} 4)$, hydrochloric acid $(\mathrm{HCl})$, potassium chloride $(\mathrm{KCl})$, 4-nitrobenzene diazonium tetra-fluoroborate, $\mathrm{N}$-hydroxysulfosuccinimide sodium salt (Sulfo-NHS), Tween 20, bovine serum albumin (BSA), N,Ndimethylformamide (DMF), ammonium nitrate, potassium phosphate, potassium citrate, uric acid sodium salt, urea, lactic acid sodium salt, bovine submaxillary gland mucin type I-S, tricaine methane sulfonate (500 $\mathrm{mg} \mathrm{ml}^{-1}$ MS-222), luminol and hydrogen peroxide were obtained from SigmaAldrich, UK. Acetonitrile (ACN), ethanol (EtOH), sodium hydroxide $(\mathrm{NaOH})$ and tetrabutylammonium perchlorate (TBAP) were sourced from Fisher Scientific, UK. N-(3dimethylaminopropyl)- N'-ethylcarbodiimide hydrochloride (EDC) was sourced from Fluka, UK.

Two biological samples were tested:

Zebrafish (whole-body): All experiments were carried following the agreed procedures in the ethical approval; they were carried out approximately the same time of the day to avoid the fluctuations in cortisol occur due to the natural circadian rhythms. Zebrafish were captured and euthanized with tricaine methane sulfonate $(500 \mathrm{mg}$ $\mathrm{ml}^{-1}$ MS-222). Whole-body cortisol extraction was performed according to the method described by Canavello et al. (2011). The yellowish lipid extract obtained was reconstituted with $1 \mathrm{ml}$ of cortisol standard dissolved in phosphate buffer saline (PBS) and stored at $4{ }^{\circ} \mathrm{C}$ for $24 \mathrm{~h}$. An alternative method was tested by repeating all the above processes except the extraction method was omitted.

Artificial saliva: the second biological sample was artificial saliva samples. A recipe outlined by West et al.
(2002) was used to prepare an artificial human saliva sample. For all cortisol and cortisone standard, there was a slight difference where they were made in artificial saliva instead of PBS $(10 \mathrm{mM})$. The electrochemical immunoassay was repeated using the above biological samples. All the above procedures were carried out for both cortisol and cortisone.

For all the electrochemical experiments conducted in this paper, a standard three electrodes setup including the $\mathrm{Ag} / \mathrm{AgCl}$ (reference electrode), nickel wire (counter electrode) and an indium tin oxide (ITO) electrode (CB50INCUV, sheet resistance 5-15 $\Omega$, dimensions $7 \times 50 \times$ $0.7 \mathrm{~mm}$, Delta Technologies Ltd., USA) (working electrode), the electrochemical experiments were conducted using a PalmSens Potentiostat (Palm Instruments, Netherlands). Copper tape was placed on one end edge of the conductive side of an ITO electrode to complete the electrical cycle.

CL detection system consists of a QHY6 charge-coupled device (CCD, QHXCCD, USA) fitted with a highresolution pixel lens ( $8 \mathrm{~mm}$, Computer, USA).

CL instrumentation shows an ITO electrode alignment under the CCD camera in a dark box, and images were recorded using Image J software and a laptop connected to the camera.

\section{Experimental procedures \\ ITO electrode modification with $-\mathrm{NH}_{2}$ group}

The ITO electrode was cycled voltammetrically from + $0.7 \mathrm{~V}$ down to $-0.5 \mathrm{~V}$ at $0.1 \mathrm{~V} \mathrm{~s}^{-1}$ using the deposition solution consisting of $0.1 \mathrm{M}$ tetrabutylammonium perchloride (TBAP) and $2 \mathrm{mM}$ 4-nitrobenzene diazonium tetrafluoroborate in acetonitrile. Then the electrode was washed with acetonitrile and placed into aqueous ethanol solution $(90: 10, \mathrm{v} / \mathrm{v})$ containing $0.1 \mathrm{M}$ potassium chloride, where the electro-formation of a phenylamine was achieved during 3 reduction-oxidation scans using cyclic voltammetry, starting at $+0.4 \mathrm{~V}$ with a sweep to $-1.25 \mathrm{~V}$ at $0.1 \mathrm{~V} \mathrm{~s}^{-1}$. This was done following Dou et al. (2012) procedure.

\section{Synthesis of antibody tagged with ferrocene}

The antibodies were chemically labelled with a redox tag, using the methodology outlined by Dou et al. (2012). This was achieved by the addition of a $10-\mu \mathrm{l}$ aliquot of $(2 \mathrm{mg}$ $\mathrm{ml}^{-1}$ ) of anti-cortisol antibody to $190 \mu \mathrm{l}$ of phosphate buffer saline (PBS) $(10 \mathrm{mM})$, and the $\mathrm{pH}$ was adjusted to $\sim 9$ using $5 \%$ aqueous potassium carbonate $\left(\mathrm{K}_{2} \mathrm{CO}_{3}\right)(5 \% \mathrm{w} / \mathrm{v})$. Then a solution of ferrocenecarboxaldehyde was dissolved in dimethylformamide (DMF) $(20 \mathrm{mg}$ in $200 \mu \mathrm{l})$ and added to the antibody solution. After an incubation of $30 \mathrm{~min}$ to permit the formation of an imine product $\mathrm{Ab}-\mathrm{N}=\mathrm{CH}-\mathrm{Fc}$; a reduction of the resulting imine to secondary amine was carried out by the addition of sodium borohydride $(2 \mathrm{mg})$ 


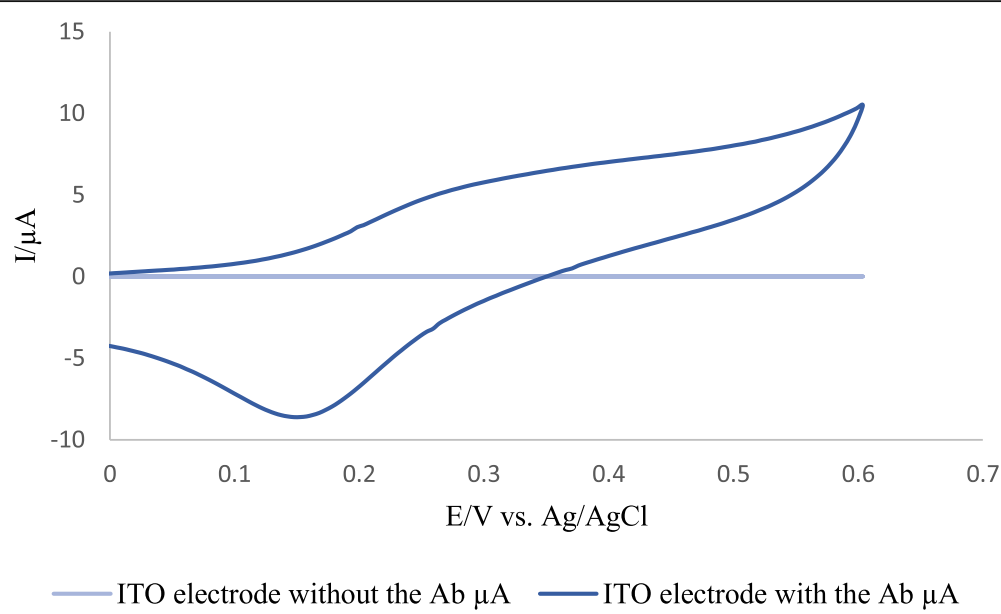

Fig. 1 Cyclic voltammogram of the modified ITO electrode surface with and without the tagged ferrocene antibody. Scan rate $100 \mathrm{mV}{ }^{-1}$. Ten millimolar PBS was the solution used to conduct all the experiments

to give $\mathrm{Ab}-\mathrm{NH}-\mathrm{CH}_{2}-\mathrm{Fc}$. This solution was left for $10 \mathrm{~min}$, afterward, the solution was readjusted to $\mathrm{pH} \sim 7$ using hydrochloric acid $(\mathrm{HCl})(0.1 \mathrm{M})$.

The antibody was purified to remove any ferrocene excess; by centrifugation (12,000 rpm for $20 \mathrm{~min})$, then the supernatant was transferred into a $2 \times$ viva spin (500, GE Healthcare, Sweden); the solution was then re-centrifuged $(12,000$ rpm for $10 \mathrm{~min}$ ), and the purified antibody on the top vial was topped up with $100 \mu \mathrm{l}$ PBS $(10 \mathrm{mM})$ and centrifuge as a washing step. The final solution was stored in the fridge $\left(4^{\circ} \mathrm{C}\right)$ until required.

\section{Immobilization of ferrocene labeled antibody onto the ITO electrode}

Coupling of the primary amine group of the modified electrode surface to the carboxylic acid groups of the antibody was carried out according to a previously reported paper by Dou et al. (2012). This was achieved by mixing a $10 \mu \mathrm{l}$

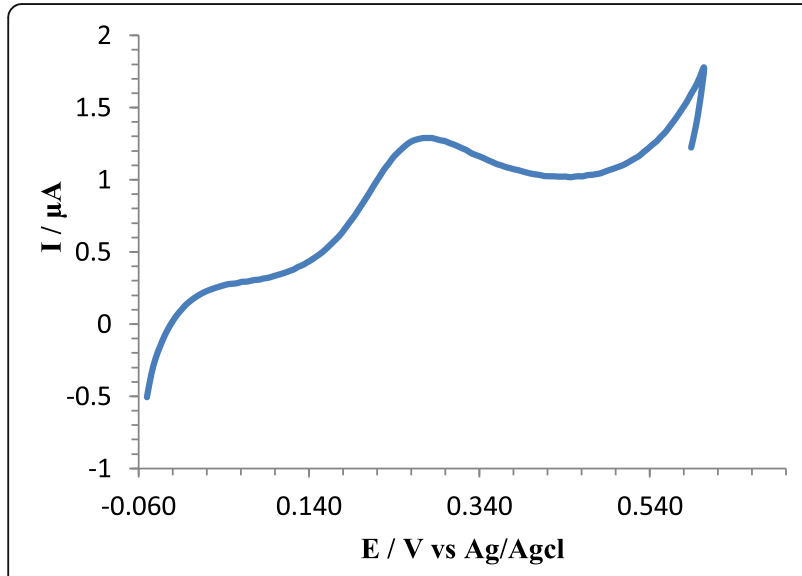

Fig. 2 Cyclic voltammogram for the oxidation of ferrocene tagged antibody to ferrocenium cation that catalyses luminol/hydrogen peroxide showing an oxidation peak at $+0.25 \mathrm{~V}$. Scan rate $10 \mathrm{mV} \mathrm{s}^{-1}$ aliquot of the ferrocene tagged antibody with an equal volume of an activation buffer consisting of $2 \mathrm{mM}$ ( $\mathrm{N}$-(3dimethylaminopropyl)- $N$ '-ethyl carbodiimide hydrochloride) (EDC) and $5 \mathrm{mM}$ ( $N$-hydroxysulfosuccinimide sodium salt) (sulfo-NHS) in $2 \mathrm{ml} \mathrm{PBS} \mathrm{(10} \mathrm{mM)} \mathrm{for} 15 \mathrm{~min}$ to activate the $-\mathrm{COOH}$ on the antibody to facilities the bonding to the electrode via an amide linkage. Subsequently, $30 \mu \mathrm{l}$ of this solution was added to the modified ITO electrode and left covered for $18 \mathrm{~h}$ in the fridge at $4{ }^{\circ} \mathrm{C}$.

\section{Stress hormones measurements}

To measure the hormones, the modified electrode was washed with $0.1 \%$ Tween $20(0.1 \mathrm{v} / \mathrm{v})$ in PBS $(10 \mathrm{mM})$ solution to effectively remove excess material from the electrode, then the electrode was treated with bovine serum albumin (BSA) $(1 \%, \mathrm{w} / \mathrm{v})$ in PBS $(10 \mathrm{mM})$ for 30 $\mathrm{min}$ as it considered sufficient time for blocking unoccupied sites on the ITO electrode. Then it was washed with $0.1 \%$ Tween 20 in PBS, and an electrochemical oxidation process was carried out, in which a cyclic voltammetry scan was carried out using PBS (10 mM) spotted onto the immobilized antibody circles starting from $-0.05 \mathrm{~V}$ up to $+0.6 \mathrm{~V}$ at scan rate $10 \mathrm{mV} \mathrm{s}^{-1}$, this involved one scan; this was carried out to convert the ferrocene attached to the antibody immobilized onto the modified ITO electrode to the ferrocenium cation.

Thirty microliters of $50 \mathrm{ng} \mathrm{ml}^{-1}$ of antigen was added to the circle on the ITO electrode containing the immobilized antibody with the ferrocenium cation attached. This was left initially for $1 \mathrm{~h}$ incubation time. Afterward, a mixture of $30 \mu \mathrm{l}$ of $20 \mathrm{mM}$ luminol and $10 \mathrm{mM}$ hydrogen peroxide is added. Light intensity was calculated using Image $J$ software after the image was taken by the CCD camera, for each measurement; there was a blank subtraction. 


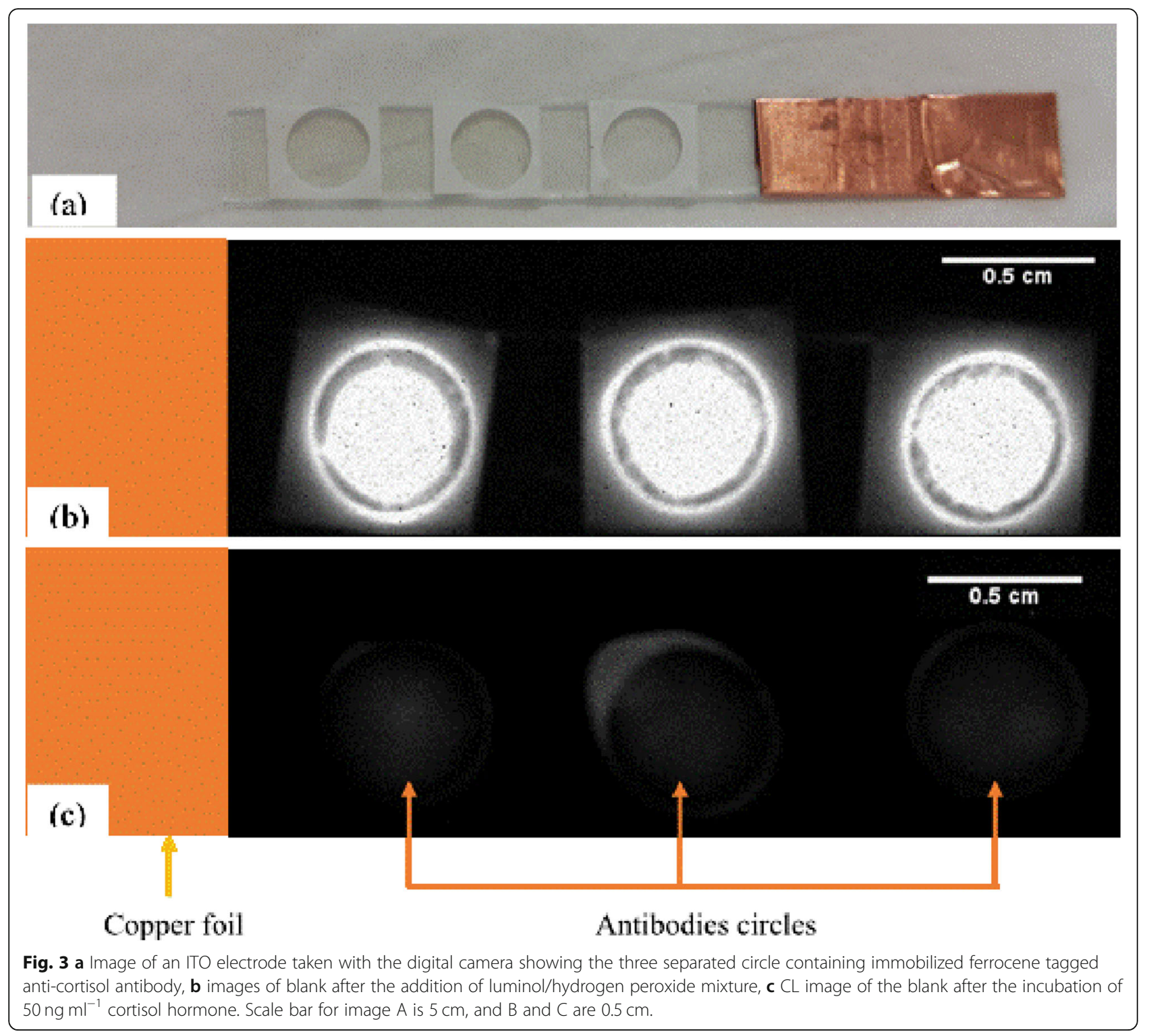

\section{Stability}

The stability of the modified ITO electrode tagged with ferrocene after oxidation was investigated. CL measurements were taken immediately, after 1 day and after 1 week to compare the results. The ITO

Table 1 The precision of immobilisation ferrocene tagged antibody on the ITO electrode surface

\begin{tabular}{llllll}
\hline Within electrode & $\begin{array}{l}\text { Circle 1 } \\
\text { RLU }\end{array}$ & $\begin{array}{l}\text { Circle 2 } \\
\text { RLU }\end{array}$ & $\begin{array}{l}\text { Circle 3 } \\
\text { RLU }\end{array}$ & Average \pm STD & RSD\% \\
\hline Electrode 1 & 253.04 & 252.97 & 249.69 & $251.90 \pm 1.91$ & 0.75 \\
Electrode 2 & 237.33 & 218.81 & 233.49 & $237.30 \pm 3.79$ & 1.61 \\
Electrode 3 & 213.02 & 199.19 & 191.11 & $200.13 \pm 9.52$ & 4.76 \\
Electrode 4 & 225.69 & 219.34 & 215.08 & $220.03 \pm 5.33$ & 2.42 \\
Final results & & & & $227.34 \pm 5.14$ & 2.38 \\
\hline
\end{tabular}

electrodes were stored in the PBS until it was needed at $4{ }^{\circ} \mathrm{C}$.

\section{Optimization of $C L$ variables}

$\mathrm{CL}$ experiments were conducted to evaluate the influence of luminol concentration, hydrogen peroxide concentration, incubation time and exposure time in order to achieve the maximum CL immunoassay emission signal. The luminol and hydrogen peroxide mixture volume for all conducted experiments was $30 \mu \mathrm{l}$.

Various concentrations $(1,5,10,20,30$ and $40 \mathrm{mM})$ of luminol were added to a fixed concentration $10 \mathrm{mM}$ of hydrogen peroxide and the mixture was spotted onto the circle on the ITO electrode to determine the highest signal. After fixing the luminol concentration that gives the maximum signal, different hydrogen peroxide 


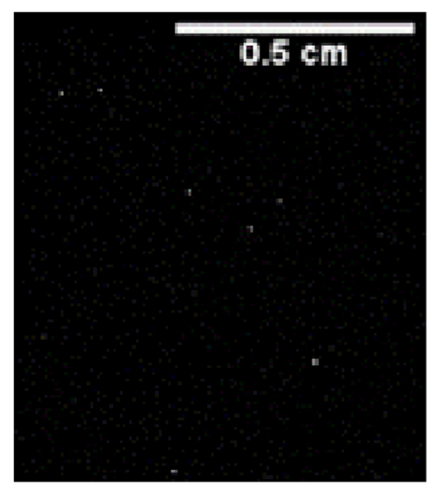

(a)

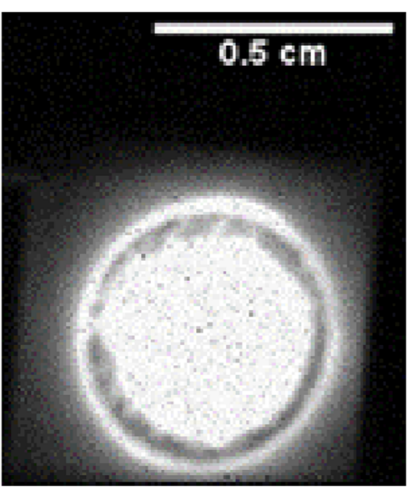

(b)

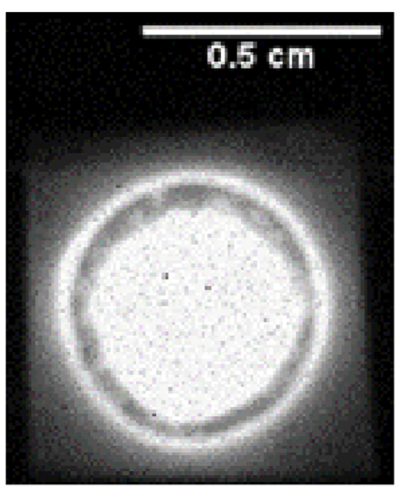

(c)

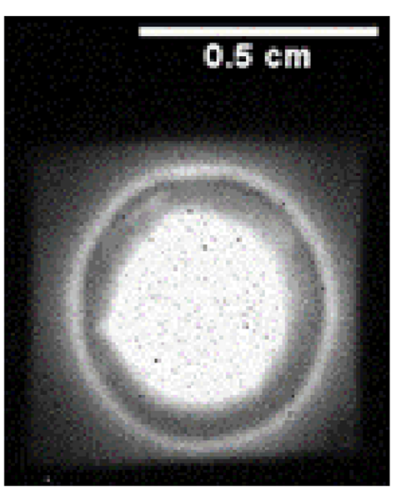

(d)

Fig. 4 Images of $C L$ signal related to ferrocene tagged antibody, (a) characterise the ferrocene tagged antibody before ferrocene oxidation, (b) immediately after the oxidation, (c) 1-day oxidation (d) after 1-week oxidation. The scale bar is $0.5 \mathrm{~cm}$.

concentrations $(1,5,10,20,30$ and $40 \mathrm{mM})$ was tested. The incubation time for the antigen was carried out varying incubation times $(5,10,15,20,30,45$ and 60 min). The optimization of exposure time was carried out by taking measurements of a time interval from 50 to $700 \mathrm{~s}$.

\section{Calibration procedures}

Cortisol and cortisone stock solutions were prepared to give a solution of $100 \mathrm{ppm}$ for each stock solution, from which the standards were prepared in PBS $(10 \mathrm{mM})$ to give working standards $\left(0.001-50 \mathrm{ng} \mathrm{ml}^{-1}\right)$ for cortisol and cortisone solution carried out.

\section{Stress hormones determination in biological sample}

In order to determine stress hormones in a biological sample including Zebrafish whole-body which is physiologically homologous to humans and other mammalian species, permitting scientists to obtain new insights into the pathways and mechanisms relevant to human clinical treatments and pathogenesis (Egan et al. 2009) and artificial saliva samples, the procedure in materials and methods were repeated for both samples individually and for both hormones (cortisol and cortisone).

\section{Interferences}

The samples selected for analysis were Zebrafish wholebody and artificial saliva samples; these have complex matrices which despite the high selectivity of the antibody-antigen reaction may have constituents that would interfere with the results. The species selected to investigate were cortisol, cortisone, prednisolone, 11deoxycortisol, progesterone, corticosterone and testosterone (all purchase from Sigma-Aldrich, UK) with a standard concentration of $50 \mathrm{ng} \mathrm{ml}^{-1}$ which was chosen be greater than the higher concentration of each compound expected to exist naturally within these samples (Yeh et al. 2013; Wood 2009), and the procedures

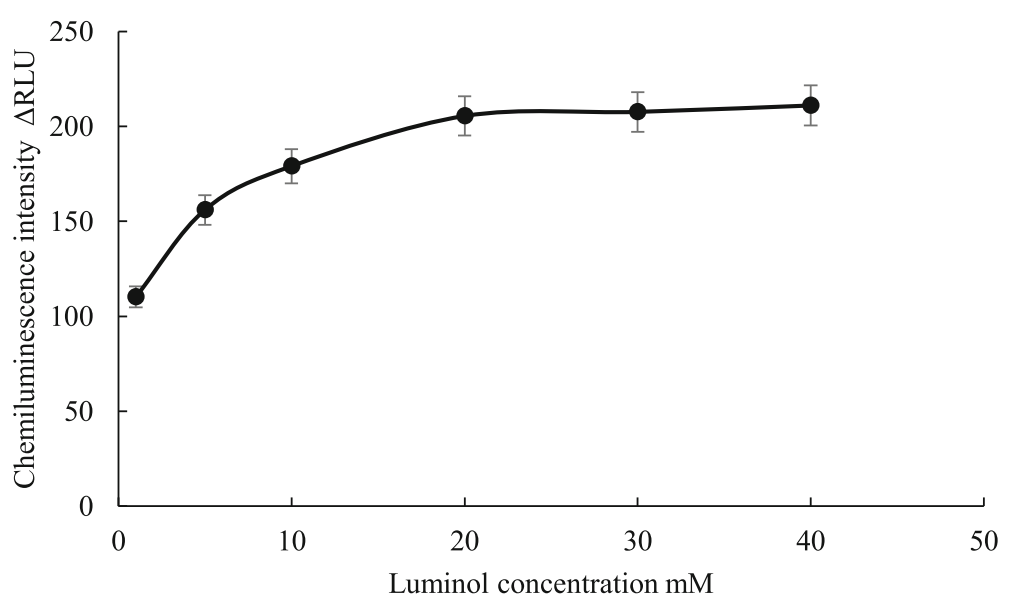

Fig. 5 A calibration curve showing the influence of luminol concentrations while keeping the concentration of hydrogen peroxide constant (10 $\mathrm{mM}$ ) on the $\mathrm{CL}$ emission signal 


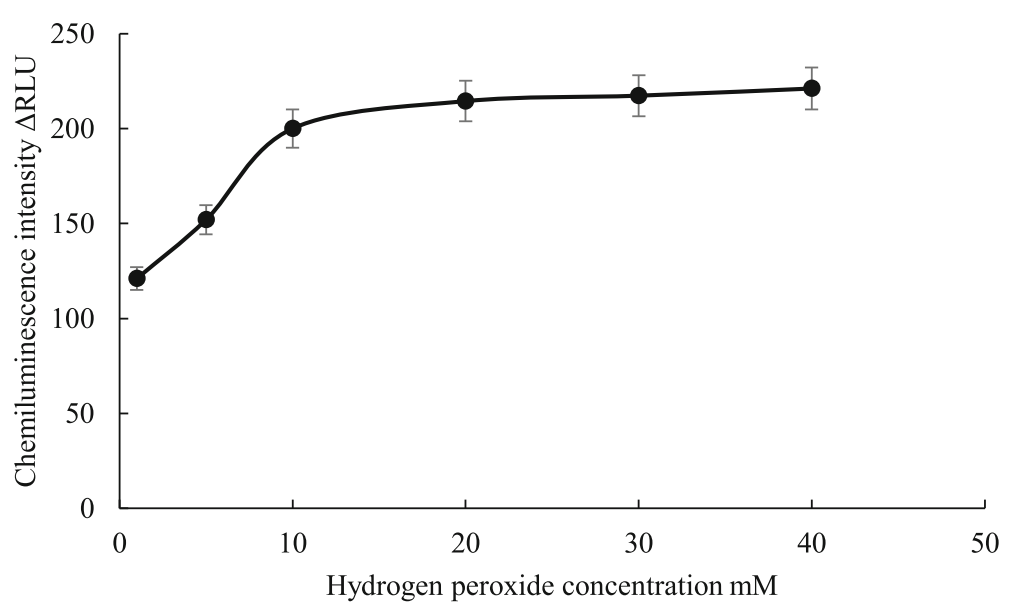

Fig. 6 Graph showing the influence of hydrogen peroxide concentration while keeping the concentration of luminol constant (20 mM) on the $C L$ emission signal

outlined in experimental procedures was used for each carried out different antigen.

For each compound, a stock solution was prepared by dissolving $5 \mathrm{mg}$ in ethanol and making the volume up to $50 \mathrm{ml}$ in PBS $(10 \mathrm{mM})$ to give a concentration of 100 $\mathrm{ppm}$, then serial dilutions were made to prepare $50 \mathrm{ng}$ $\mathrm{ml}^{-1}$ working solution.

\section{Comparison study with standard Enzyme-Linked Immunosorbent Assay (ELISA)}

For comparison, a standard ELISA method was performed using a human salivary cortisol assay kit (ab 154996- cortisol ELISA kit, Abcam, UK). The ELISA assay was carried out as per the instructions provided. The absorbance of the sample was measured at $450 \mathrm{~nm}$ within 30 min of stop solution addition; a Labtech International plate reader was used to make the measurements.

\section{Results and discussion}

Characterization of ferrocene tagged anti-cortisol immobilized onto ITO electrode surface

To confirm the success of the immobilization process, cyclic voltammetry measurements were conducted for the modified ITO electrode surface without the antibody (blank) and with the tagged ferrocene antibody. This step was done following Kevin et al. characterization of ferrocene tagged antibodies (Wright et al. 2018). Figure 1 shows the comparison between blank ITO electrode surface and modified ITO electrode surface with the tagged ferrocene antibody using cyclic voltammetry.

An oxidation peak at $+0.25 \mathrm{~V}$ from Fig. 1 was seen for the ITO electrode with the tagged ferrocene antibody. This confirms the oxidation of the ferrocene to the ferrocenium cation on the ITO electrode surface with a reduction peak at $+0.25 \mathrm{~V}$, as would expect no peak was seen for the blank ITO electrode.

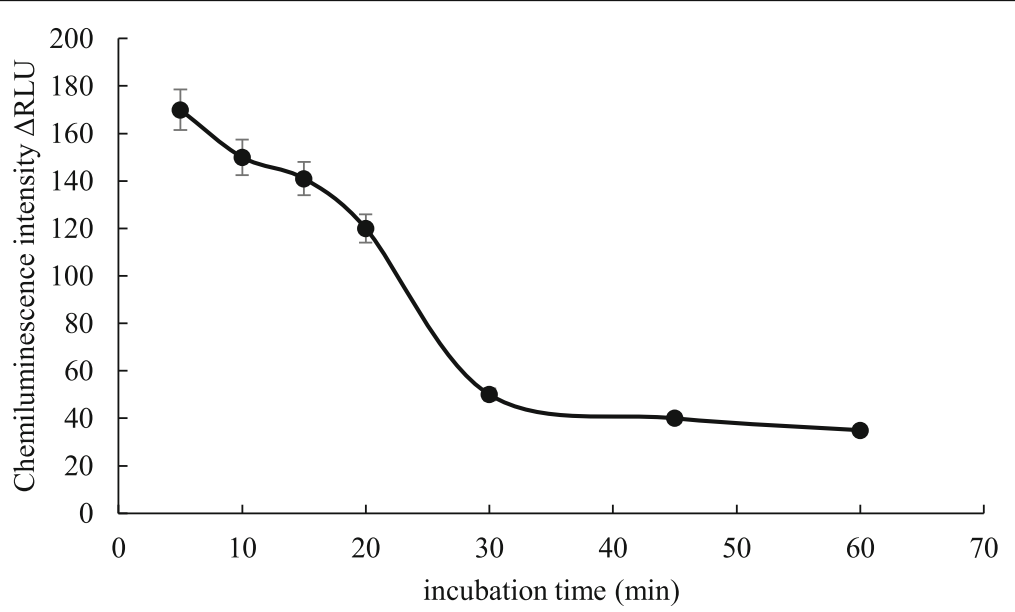

Fig. 7 The graph shows the effect of different incubation time on the $\mathrm{CL}$ signal after the addition of $30 \mu \mathrm{l}$ of $50 \mathrm{ng} \mathrm{ml}^{-1}$ of cortisol standard solution. 


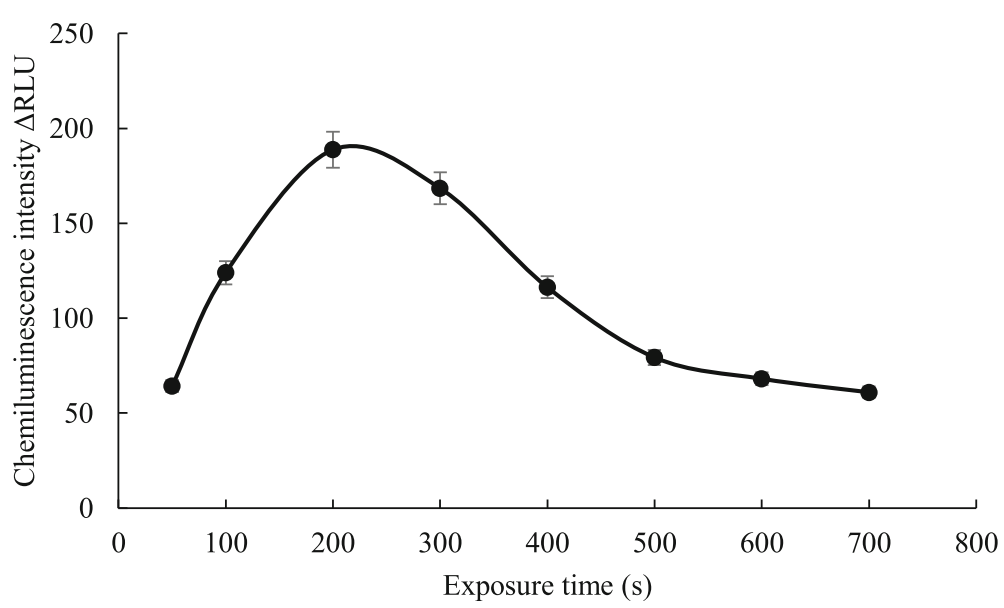

Fig. 8 The graph for exposure time optimisation after the addition of luminol $(20 \mathrm{mM})$ and hydrogen peroxide $(10 \mathrm{mM})$ mixture over the time interval from 50 to $700 \mathrm{~s}$ showing the highest $\mathrm{CL}$ signal at $200 \mathrm{~s}$.

\section{Oxidation of $\mathrm{Ab}-\mathrm{Fc}$ on the surface}

The first step to carry the CL procedure was the oxidation of the ferrocene to ferrocenium cation using cyclic voltammetry as can be seen in Fig. 2. The scan rate was $10 \mathrm{mV} \mathrm{s}^{-1}$ to enable more time at a set potential which would kinetically favor the ferrocene oxidation (Partington et al. 2018).

The oxidation peak at $+0.25 \mathrm{~V}$ shown in Fig. 2 represents the ferrocene oxidation to ferrocenium cation. This is essential for the CL reaction to occur with the iron located in the ferrocene carboxaldehyde acting as a catalyst for luminol/hydrogen peroxide (Wilson and Schiffrin 1998). The next step was to investigate the ferrocenium cation ability as a catalyst to luminol and hydrogen peroxide mixture to produce the $\mathrm{CL}$ emission signal.

\section{Investigation of $\mathrm{CL}$ emission}

To investigate the CL emission before and after the addition of an antigen, a preliminary experiment was conducted by adding $30 \mu \mathrm{l}$ of luminol and hydrogen peroxide mixture to the ferrocene tagged antibody before and after the incubation with $50 \mathrm{ng} \mathrm{ml}^{-1}$ cortisol hormone which was chosen because it has the highest concentration, so it would clear CL signal (Fig. 3).

Figure 3 demonstrated the applicability of ferrocene to be used as a catalyst in the luminol/hydrogen peroxide reaction (Hassan et al. 2014). As can be seen, a decrease in the CL signal from 227.3 RLU for the blank (Fig. 3b) to 21.5 RLU after the addition of the antigen ( $50 \mathrm{ng} \mathrm{ml}^{-1}$ cortisol standard solution) (Fig. 3c) was observed.

As would be expected the $\mathrm{CL}$ emission signal was highest without the addition of the antigen. The signal then decreased when the antigen was added because it boundd to the antibody thus reducing the electron transfer at the surface (blocking effect) (Dou et al. 2012) yielding a lower CL signal.
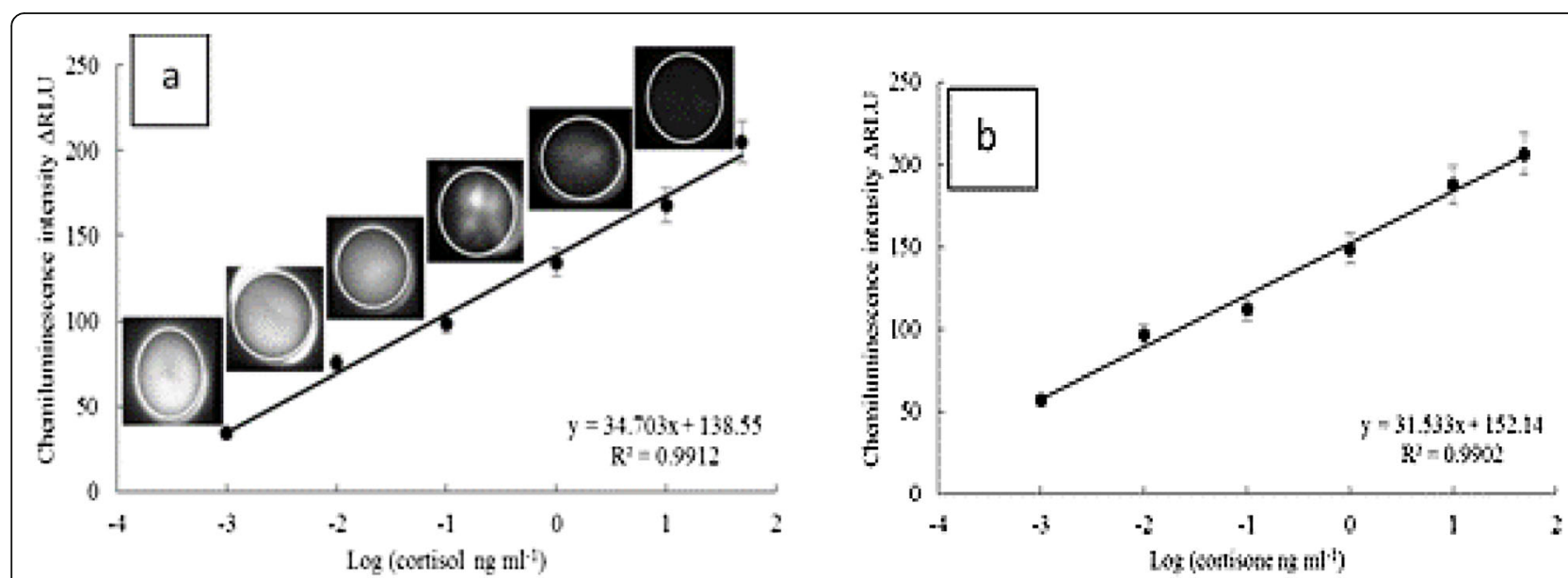

Fig. 9 Calibration curve of $\mathbf{a}$ cortisol and $\mathbf{b}$ cortisone standard solutions with concentrations from 0 to $50 \mathrm{ng} \mathrm{ml}^{-1}$. Standards plotted against the $\Delta R L U$ (relative light unit) emission response, insert in the figure $\mathbf{a} \mathrm{CL}$ image of each standard cortisol solution. 

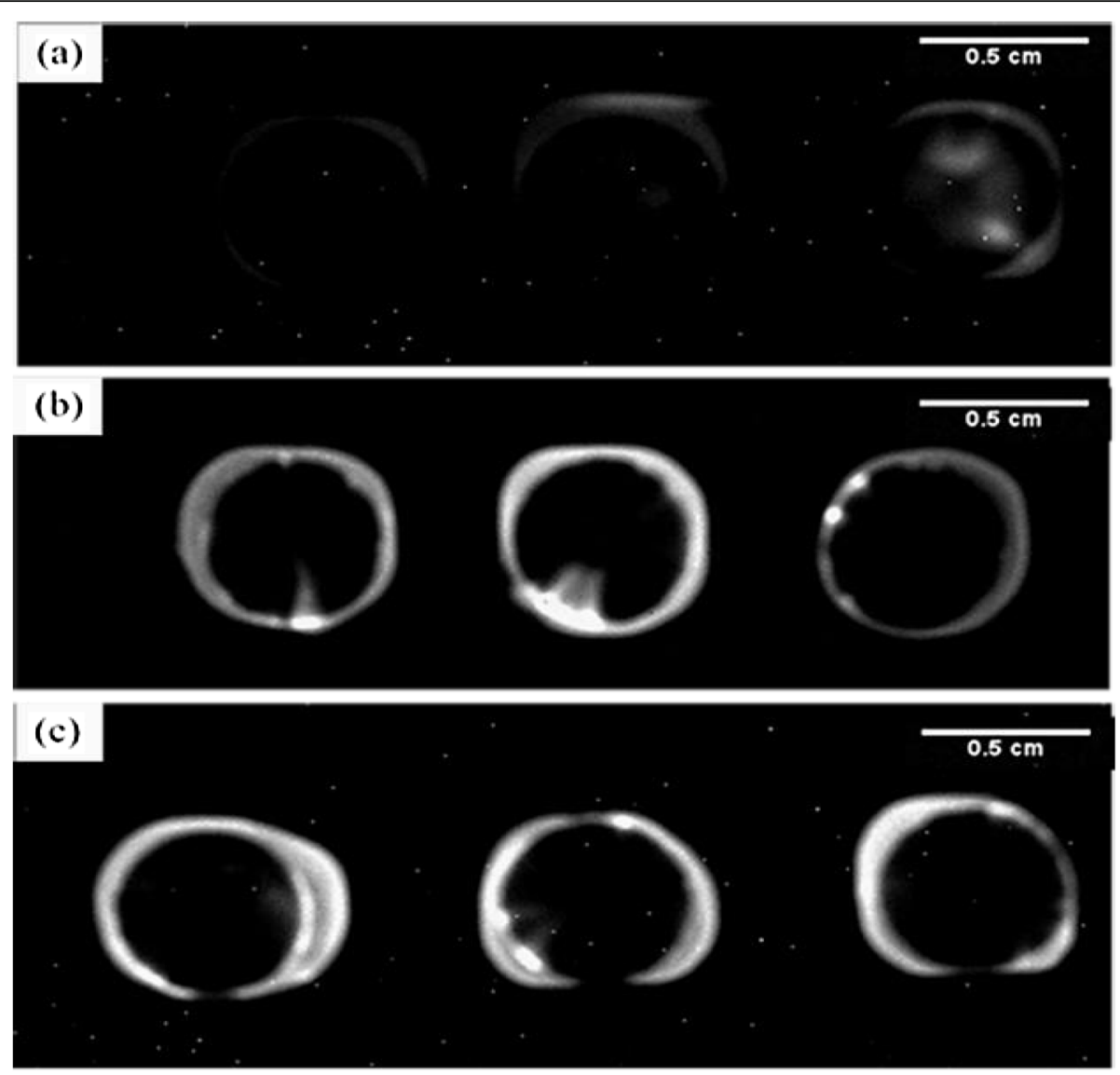

Fig. $10 \mathrm{CL}$ image of Zebrafish whole-body sample spiked standard cortisol solution (50 $\mathrm{ng} \mathrm{ml}^{-1}$ ) added to ferrocene anti-cortisol antibody immobilized onto modified ITO electrode $\mathbf{a}$ without extraction, $\mathbf{b}$ with extraction and $\mathbf{c}$ fish sample without the addition of standard and without extraction. Scale bar is $0.5 \mathrm{~cm}$

Experiments were carried out to investigate the reproducibility and effectiveness of the ferrocene tagged antibody immobilization on the ITO electrode surface. The previously described experiment was repeated on three circles within the same electrode (intra-assay) and different circles on different electrodes (inter-assay) individually for four electrodes. The results are summarized in Table 1.

The data shown in Table 1 for the RSD \% for three circles within the same electrode was between 0.75 and $4.76 \%$, whereas the RSD\% between different circles of different electrodes was $2.38 \%$. This shows that there is no significant difference in CL signal between circles on the same electrode and circles on different electrodes.

Table 2 The Recovery and RSD values of cortisol and cortisone standard solution spiked in the Zebrafish whole-body sample ( $n$ = 3)

\begin{tabular}{llll}
\hline Analyte & $\begin{array}{l}\text { Conc. added } \\
\left(\mathrm{ng} \mathrm{ml}^{-1}\right)\end{array}$ & Rec (\%) & RSD \% \\
\hline Cortisol & 50 & 91.0 & 1.25 \\
Cortisone & 10 & 90.0 & 2.00 \\
\hline
\end{tabular}

\section{The stability of ferrocenium cation}

Simplicity is the key point in constructing a point of care system; therefore, the stability of ferrocene tagged antibody after oxidation is important so that it does not need to be oxidized just before measurement. To investigated the stability images were captured for the three circles containing the ferrocene tagged anti-cortisol antibody before oxidation, directly after the ferrocene oxidation by luminol/hydrogen peroxide mixture, 1 day and 1 week after the ferrocene oxidation after being kept in $10 \mathrm{mM}$ PBS solution for the whole period of experiment at $4{ }^{\circ} \mathrm{C}$.

Figure 4 shows promising results for ferrocene stability, where (a) no light emission was observed because the non-oxidized ferrocene does not catalyse the luminol/hydrogen peroxide reaction (b) immediately after oxidation which shows an increase in the signal up to 224.01 RLU as expected because of the ferrocenium cation action as a catalyst (Jain 2013) where the ferrocenium cation breaks down the hydrogen peroxide creating hydrogen radical which reacts with luminol and emitting the CL signal (c) and (d) shows a minor 


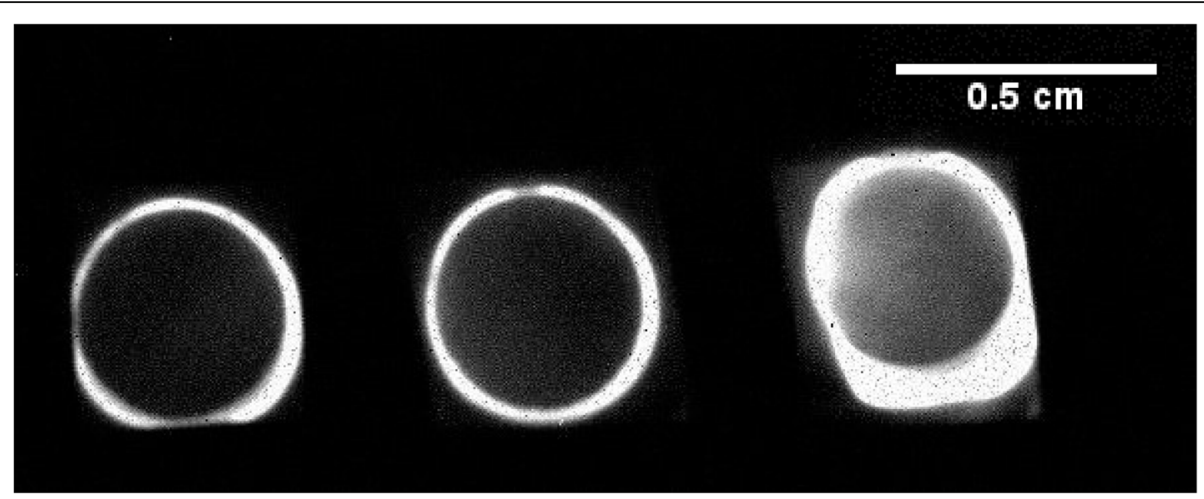

Fig. 11 Represent the signal after the addition of artificial saliva spiked with cortisol standard solution $10 \mathrm{ng} \mathrm{ml}^{-1}$. The scale bar is $0.5 \mathrm{~cm}$

decrease in the CL measurement giving an RLU of 220.12 and 196.65 for the ferrocene tagged antibody after oxidation and storage in $10 \mathrm{mM}$ PBS for 1 day and 1 week respectively which does not impact the analysis.

\section{Optimization of operating variables}

The effect of different operating conditions (luminol concentration, hydrogen peroxide concentration, incubation time and exposure time) on the CL emission signal were investigated to achieve the maximum CL signal.

\section{Influence of luminol concentration}

Experiments were carried out to evaluate the influence of different luminol concentrations ranging from 1 to $40 \mathrm{mM}$ on the CL signal.

$\mathrm{CL}$ experiments were carried out at different luminol concentrations ranging from 1 to $40 \mathrm{mM}$ ) as cited in Fig. 5, where increasing the concentration of luminol leads to an increase in the CL signal between 1 and $20 \mathrm{mM}$ where 20 $\mathrm{mM}$ luminol concentration reaches the optimum signal of 205.4 RLU. Self-absorption was seen for higher concentrations (Chen et al. 2012). And therefore, $20 \mathrm{mM}$ luminol was used for all experiments within this paper.

\section{Influence of hydrogen peroxide concentration}

To study the effect of hydrogen peroxide concentrations on CL emission signal different concentrations in the range of (1-40 $\mathrm{mM})$ were tested.

A similar trend to changing concentrations for luminol was observed for hydrogen peroxide (as shown in Fig. 6). The CL emission signal increased with the increasing

Table 3 The Recovery and RSD values of cortisol and cortisone standard solution spiked in the artificial saliva sample for three different electrodes

\begin{tabular}{llll}
\hline Analyte & $\begin{array}{l}\text { Conc added } \\
\left(\mathrm{ng} \mathrm{ml}^{-1}\right)\end{array}$ & Rec (\%) & RSD \% \\
\hline Cortisol & 10 & 92.59 & $2.04 \%$ \\
Cortisone & 25 & 90.73 & $1.98 \%$ \\
\hline
\end{tabular}

concentrations up to $10 \mathrm{mM}$. Above that concentration, the CL emission signal was seen to stabilise up to 40 $\mathrm{mM}$; therefore, $10 \mathrm{mM}$ hydrogen peroxide was chosen as an optimum concentration.

\section{Influence of incubation time}

The incubation time of antibody-antigen interaction was tested. As expected, the incubation time of antibodyantigen interaction was $30 \mathrm{~min}$ as shown in Fig. 7 where the CL RLU increased to $168 \mathrm{RLU}$ at $5 \mathrm{~min}$; this may be due to insufficient time to complete the interaction between the antibody and the antigen. Then the signal reached the lowest signal between 30 and $60 \mathrm{~min}$ with no significant difference; therefore, $30 \mathrm{~min}$ was chosen for further experiments.

\section{Influence of exposure time}

Exposure time is a fundamental parameter for an economical point of care system. It can be defined as the length of time that an image required to be exposed to the CCD camera to acquire the highest CL signal. Consequently, it is important to study its influence on the CL signal of over time intervals from 50 to $700 \mathrm{~s}$.

Figure 8 shows that the CL emission signal initially increased with exposure time up to $200 \mathrm{~s}$, and after this time, the CL signal decreases. Therefore, $200 \mathrm{~s}$ was deemed more than sufficient to establish the optimum CL signal and used in all subsequent studies.

\section{Calibration curve}

To determine cortisol and cortisone, calibration curves were obtained by preparing a set of standards solutions at concentrations ranging from 0 to $50 \mathrm{ng} \mathrm{ml}^{-1}$, and the CL immunoassay was performed.

As expected, the $\Delta$ RLU increased with as the concentration of the standard solutions increased (Fig. 9a, b) giving linearity over the range required to analyse the target analyte in the real sample and with correlation coefficients of 0.9912 and 0.9902 for cortisol and cortisone. 

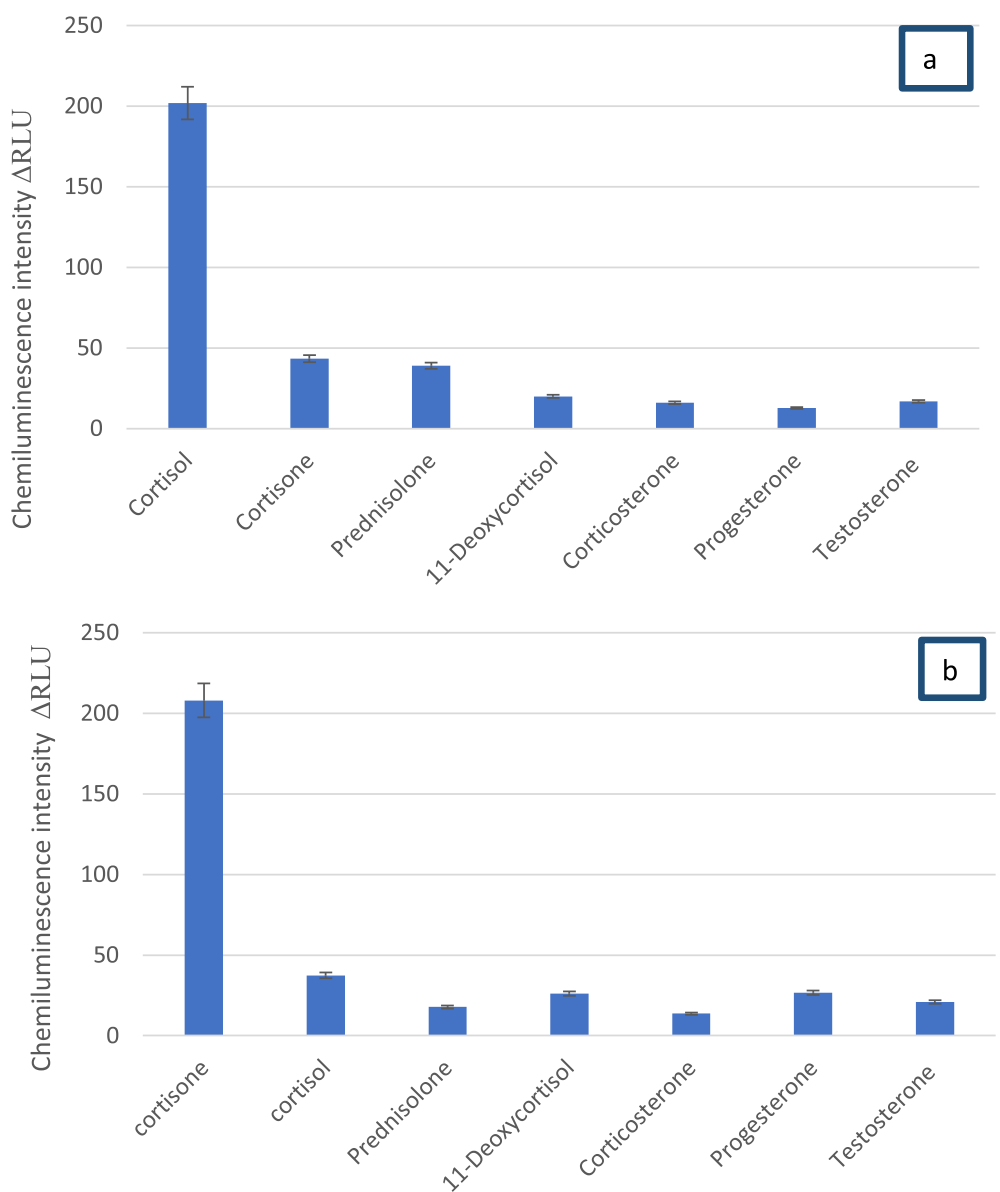

Fig. 12 Column chart specifies the similar structure compounds potential interference with a ferrocene tagged anti-cortisol antibody and $\mathbf{b}$ ferrocene tagged anti-cortisone antibody

Also, the limit of detection for cortisol and cortisone were 0.47 and $0.34 \mathrm{pg} \mathrm{ml}^{-1}$, respectively showing excellent analytical data for stress hormones determination.

\section{Determination of target analyte in Zebrafish whole-body and artificial saliva samples}

Further experiments were carried out to determine the concentration of stress hormones in Zebrafish wholebody and artificial saliva samples:

\section{Zebrafish whole-body sample}

Measurements were carried out with and without the extraction procedure Fig. 10 shows CL emission for (a) a real sample spiked with $1 \mathrm{ml}$ of $50 \mathrm{ng} \mathrm{ml}^{-1}$ of cortisol standard solution and the extraction method was carried out giving an RLU of 22.4, (b) a real sample spiked with $1 \mathrm{ml}$ of $50 \mathrm{ng} \mathrm{ml}^{-1}$ without extraction giving an RLU of 29.0. A clear observation was that there was a decrease in the light intensity for the real sample with extraction and without extraction compared with the standard solution of cortisol that gave an RLU of 21.5. As the difference in the CL signal was small, the use of the sample without the extraction was acceptable with calibration.

An observation of a white round edge for the reaction cycle can be explained by "the coffee ring effect" because the solution evaporate more quickly at the edges than at the centre, and the remaining solution at the center 1 moved outward this movement created concentrated layers forming a dense ring (Shimoni et al. 2014).

The data obtained was used to calculate the recovery and RSD for both cortisol and cortisone as summarized in Table 2.

The data obtained from Table 2 indicates the good recovery for both hormones where cortisol recovery was $91.0 \%$ and cortisone was $90.0 \%$. Also the values of the RSD ranged between $1.25 \%$ and $2.0 \%$ for cortisol and cortisone respectively. These results show the applicability of the immunoassay protocol followed by CL detection for the determination of stress hormones in Zebrafish whole-body sample. 


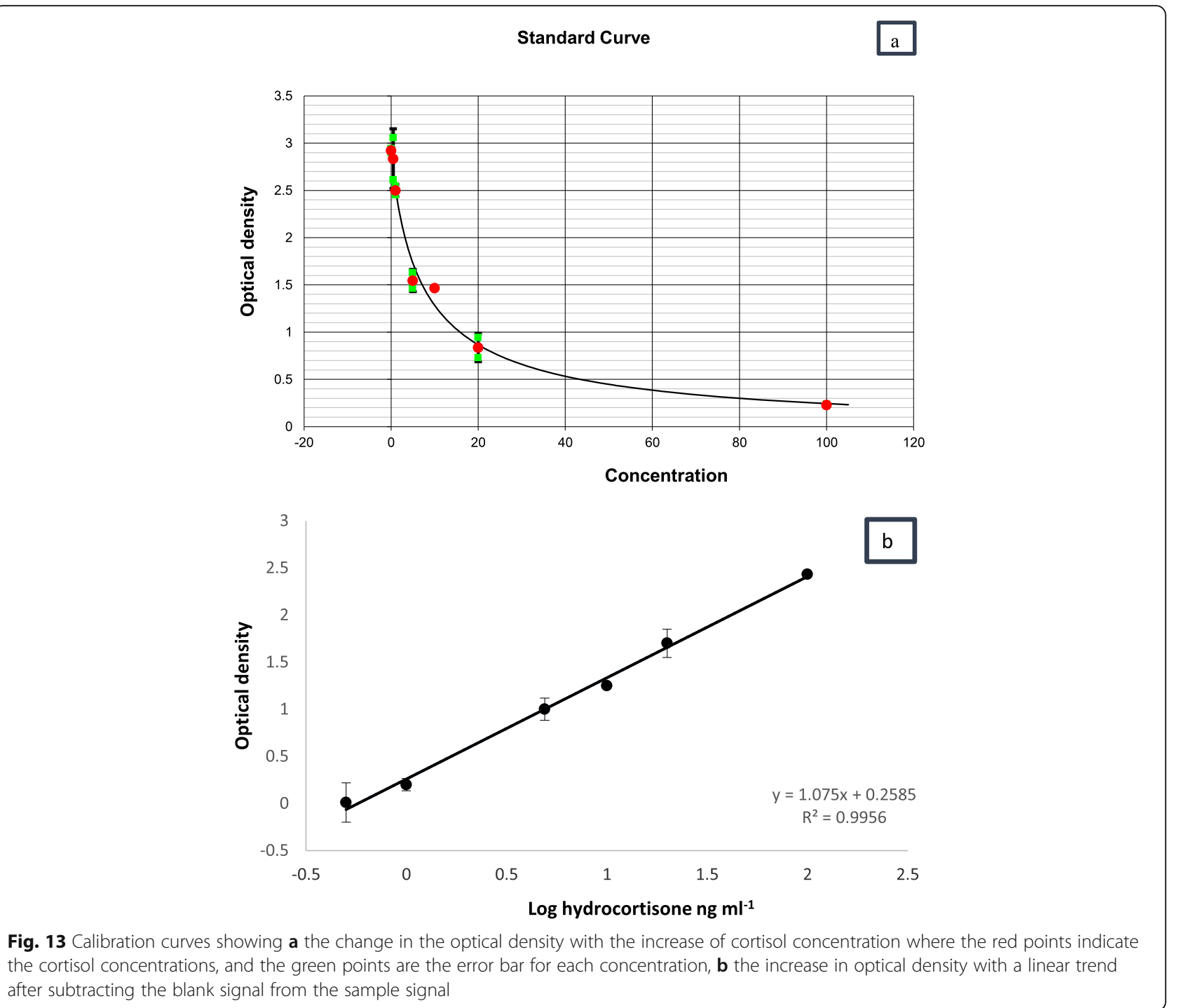

\section{Artificial saliva}

The prepared saliva was spiked with $10 \mathrm{ng} \mathrm{ml}^{-1}$ cortisol and $25 \mathrm{ng} \mathrm{ml}^{-1}$ cortisone standard solutions, and the resulting solutions were incubated for $30 \mathrm{~min}$ before measuring the $\mathrm{CL}$ emission (Fig. 11.)

As can be seen from Fig. 11, the signal decreased due to the reaction between the antibody and antigen. The data obtained from cortisol and cortisone were summarized in Table 3.

From Fig. 11 and Table 3, the recovery was calculated giving a recovery of $92.59 \%$ and $90.73 \%$ for cortisol and cortisone respectively. Another statistical parameter was calculated which was the RSD \% which was $2.04 \%$ of cortisol and less value for cortisone giving a value of $1.98 \%$.

\section{Interferences}

The antibody-antigen interaction is very selective, and the main interferences were likely to have similar structures which could interact with the anti-cortisol and anticortisone antibodies immobilized onto the modified ITO electrode resulting in false results. A range of similar compound was selected, and CL images were acquired using optimum conditions for cortisol and cortisone.

As can be seen from Fig. 12a, cortisone, prednisolone, 11-deoxycortisol, corticosterone, progesterone and testosterone had very little effect on the anti-cortisol antibody where the RLU for these compounds ranged from 12 to 38. There was slightly more of an effect for cortisone where the RLU was 43 , but the CL emission for cortisol was 205 RLU. It can be said that the presence of these compounds does not impact on the adopted immunoassay in this study. Figure $12 \mathrm{~b}$ shows also the effect of similar compounds on the ferrocene tagged anticortisone and as expected there was a minor interference effect from these compounds with slightly more effect from cortisol with 37 RLU, but this inference can be 
considered negligible compared with cortisone RLU of 206.42 .

\section{Commercial ELISA kit}

To evaluate the immunoassay protocol used in this paper, a comparison with a reference method was carried out. Stress hormone is usually tested with a traditional ELISA assay which is performed in the majority of hospital service laboratories. Therefore, it was decided to test the stress hormones using a commercial ELISA and compare the results with the immunoassay protocol.

Figure $13 \mathrm{a}$ and $\mathrm{b}$ give the relationship between the optical intensity signal and the standardized concentrations of cortisol. It can be observed that the optical intensity signal increase with the increase of the concentration of the cortisol to give a linear calibration curve with $R^{2}$ of 0.995 . The Zebrafish whole-body sample was tested giving a concentration of $44.56 \mathrm{ng} \mathrm{m}^{-1}$ (with extraction) and $46.78 \mathrm{ng} \mathrm{ml}^{-1}$ (without extraction) which confirms that the extraction procedure can be omitted removing additional steps.

There was a good agreement with the proposed method where $R^{2}$ for cortisol was 0.991 compared with $R^{2}$ for cortisol using ELISA kit was 0.995 with a LOD of $0.12 \mathrm{ng} \mathrm{ml}^{-1}$ (from the data sheet provided by the Abcam company). This applied also for the concentration obtained by the standard method (ELISA) mentioned above compared with the CL immunoassay concentration $\left(47.86 \mathrm{ng} \mathrm{ml}^{-1}\right)$. As a result, it can be concluded from the results obtained from the conventional tests that the development of a sensitive CL immunoassay for stress hormone was achieved.

\section{Conclusion}

A new inexpensive rapid CL immunoassay method has been developed to detect stress hormones with reproducible electrochemical immobilization of the antibody in which ferrocene was used as a catalyst for CL detection. The ferrocene was electrochemically converted to the ferrocenium cation. The stability of the oxidized antibody with the ferrocene moiety was investigated, and the results showed high stability after oxidation over 1 week which simplified the proposed protocol.

Calibration curves for both cortisol and cortisol were constructed and give LOD at 0.47 and $0.34 \mathrm{pg} \mathrm{m}^{-1}$ for cortisol and cortisone with correlation coefficients of 0.9912 and 0.9902 which indicates a high sensitivity of this method. The new method had much lower limits of detection compared to the standard ELISA test $(0.12 \mathrm{ng}$ $\mathrm{ml}^{-1}$ ). Potential interferences were examined, and the results confirmed the selectivity of this protocol.

\section{Abbreviation}

BSA: Bovine serum albumin; CAN: Acetonitrile; CCD: Charge-coupled device; $\mathrm{CL}$ : Chemiluminescence; EDC: N-(3-Dimethylaminopropyl)- N'- ethylcarbodiimide hydrochloride; ELISA: Enzyme-linked immunosorbent assay; FcCHO: Ferrocenecarboxylaldehyde; GCs: Glucocorticoids; ITO: Indium tin oxide (ITO); PBS: Phosphate buffer saline; RLU: Relative light unit; SulfoNHS: N-Hydroxysulfosuccinimide sodium salt; TBAP: Tetrabutylammonium perchlorate

\section{Acknowledgments}

This work was funded by the Ministry of Higher Education and Scientific Research in Iraq. The authors would like to thank Mustansiriyah UniversityBaghdad-Iraq for its support in the present work. We are grateful for the help from the academic and technical staff in the Department of Chemistry and Biochemistry at the University of Hull UK.

\section{Authors' contributions}

All authors approved the final version of the manuscript for publication

\section{Funding}

Ministry of Higher Education and Scientific Research in Iraq

\section{Availability of data and materials}

All raw data used in this manuscript are available and could be supplied upon request

\section{Competing interests}

The authors declare that they have no competing interests.

\section{Author details}

${ }^{1}$ Department of Chemistry, College of Science, Mustansiriyah University, Baghdad, Iraq. ${ }^{2}$ Departement of Chemistry and Biochemistry, University of Hull, Hull, United Kingdom.

Received: 25 September 2019 Accepted: 8 November 2019

Published online: 06 December 2019

\section{References}

Adcock JL, Barnett NW, Francis PS. Chemiluminescence | Overview $\boldsymbol{i}$. In: Worsfold P, Poole C, Townshend A, Miró M, editors. Encyclopedia of analytical science (third edition). Oxford: Academic Press; 2019.

Ammann AA, Macikova P, Groh KJ, Schirmer K, Suter MJ. LC-MS/MS determination of potential endocrine disruptors of cortico signalling in rivers and wastewaters. Anal Bioanal Chem. 2014;406:7653-65.

Ashley N, Barboza P, Macbeth B, Janz D, Cattet M, Booth R, Wasser S. Glucocorticosteroid concentrations in feces and hair of captive caribou and reindeer following adrenocorticotropic hormone challenge. Gen Comp Endocrinol. 2011;172:382-91.

Barcellos LG, Ritter F, Kreutz LC, Quevedo RM, Da Silva LB, Bedin AC, Finco J, Cericato L. Whole-body cortisol increases after direct and visual contact with a predator in zebrafish, Danio rerio. Aquaculture. 2007;272:774-8.

Canavello PR, Cachat JM, Beeson EC, Laffoon AL, Grimes C, Haymore WA, Elegante MF, Bartels BK, Hart PC, Elkhayat SI. Measuring endocrine (cortisol) responses of zebrafish to stress. Zebrafish neurobehavioral protocols. 2011: $135-42$.

Ceccato F, Antonelli G, Barbot M, Zilio M, Mazzai L, Gatti R, Zaninotto M, Mantero F, Boscaro M, Plebani M. The diagnostic performance of urinary free cortisol is better than the cortisol: cortisone ratio in detecting de novo Cushing's syndrome: the use of a LC-MS/MS method in routine clinical practice. Eur J Endocrinol. 2014;171:1-7.

Chen W, Hong L, Liu A-L, Liu J-Q, Lin X-H, Xia X-H. Enhanced chemiluminescence of the luminol-hydrogen peroxide system by colloidal cupric oxide nanoparticles as peroxidase mimic. Talanta. 2012;99:643-8.

Corbalán-tutau D, Madrid JA, Nicolás F, Garaulet M. Daily profile in two circadian markers "melatonin and cortisol" and associations with metabolic syndrome components. Physiol Behav. 2014;123:231-5.

Del Corral P, Schurman RC, Kinza SS, Fitzgerald MJ, Kordick CA, Rusch JL, Nadolski JB. Salivary but not plasma cortisone tracks the plasma cortisol response to exercise: effect of time of day. J Endocrinol Investig. 2016;39:315-22.

Dou YH, Haswell SJ, Greenman J, Wadhawan J. Voltammetric immunoassay for the detection of protein biomarkers. Electroanalysis. 2012;24:264-72.

Egan RJ, Bergner CL, Hart PC, Cachat JM, Canavello PR, Elegante MF, Elkhayat SI, Bartels BK, Tien AK, Tien DH, Mohnot S, Beeson E, Glasgow E, Amri H, Zukowska Z, Kalueff AV. Understanding behavioral and physiological 
phenotypes of stress and anxiety in zebrafish. Behav Brain Res. 2009;205:3844.

Erickson D, Singh RJ, Sathananthan A, Vella A, Bryant SC. Late-night salivary cortisol for diagnosis of Cushing's syndrome by liquid chromatography/ tandem mass spectrometry assay. Clin Endocrinol. 2012;76:467-72.

Gao W, Stalder T, Kirschbaum C. Quantitative analysis of estradiol and six other steroid hormones in human saliva using a high throughput liquid chromatography-tandem mass spectrometry assay. Talanta. 2015;143:353-8.

Gatti R, Antonelli G, Prearo M, Spinella P, Cappellin E, Elio F. Cortisol assays and diagnostic laboratory procedures in human biological fluids. Clin Biochem. 2009:42:1205-17

Hassan Ml, Khan P, Idrees D, Moxley MA, Corbett JA, Ahmad F, von Figura G, Sly WS, Waheed A. Luminol-based chemiluminescent signals: clinical and non-clinical application and future uses. Appl Biochem Biotechnol. 2014;173:333-55.

IZAWA S, MIKI K, TSUCHIYA M, MITANI T, MIDORIKAWA T, FUCHU T, KOMATSU T, TOGO F. Cortisol level measurements in fingernails as a retrospective index of hormone production. Psychoneuroendocrinology. 2015;54:24-30.

Jain V. Effect of catlyst on luminol-hydrogen peroxide-water chemiluminescence system. Asian Journal of Pharmaceutical Analysis. 2013;3:138-40.

Kartsova L, Strel'nikova E. Separation of exogenous and endogenous steroid hormones by micellar high-performance thin-layer chromatography. J Anal Chem. 2007;62:872-4.

Kaushik A, Vasudev A, Arya SK, Pasha SK, Bhansali S. Recent advances in cortisol sensing technologies for point-of-care application. Biosens Bioelectron. 2014; 53:499-512.

Liu F, Zhang C. A novel paper-based microfluidic enhanced chemiluminescence biosensor for facile, reliable and highly-sensitive gene detection of Listeria monocytogenes. Sensors Actuators B Chem. 2015;209:399-406.

Luo A, EL Gierari ETM, Nally LM, Sturmer LR, Dodd D, Shi R-Z. Clinical utility of an ultrasensitive urinary free cortisol assay by tandem mass spectrometry. Steroids. 2019;146:65-9.

Luo M, Chen X, Zhou G, Xiang X, Chen L, Ji X, He Z. Chemiluminescence biosensors for DNA detection using graphene oxide and a horseradish peroxidase-mimicking DNAzyme. Chem Commun. 2012;48:1126-8.

Miller R, Plessow F, Rauh M, Gröschl M, Kirschbaum C. Comparison of salivary cortisol as measured by different immunoassays and tandem mass spectrometry. Psychoneuroendocrinology. 2013;38:50-7.

Oßwald A, Wang R, Beuschlein F, Hartmann MF, Wudy SA, Bidlingmaier M, Zopp S, Reincke M, Ritzel K. Performance of LC-MS/MS and immunoassay based 24-h urine free cortisol in the diagnosis of Cushing's syndrome. J Steroid Biochem Mol Biol. 2019;190:193-7.

Partington LI, Atkin SL, Kilpatrick ES, Morris SH, Piper M, Lawrence NS, Wadhawan JD. Electrochemical measurement of antibody-antigen recognition biophysics: Thermodynamics and kinetics of human chorionic gonadotropin (hCG) binding to redox-tagged antibodies. J Electroanal Chem. 2018;819:533-41.

Protopopova A. Effects of sheltering on physiology, immune function, behavior, and the welfare of dogs. Physiol Behav. 2016;159:95-103.

Russell E, Koren G, Rieder M, Van Uum SH. The detection of cortisol in human sweat: implications for measurement of cortisol in hair. Ther Drug Monit. 2014;36:30-4.

Sánchez-guijo A, Hartmann MF, Shi L, Remer T, Wudy SA. Determination of free cortisol and free cortisone in human urine by on-line turbulent flow chromatography coupled to fused-core chromatography-tandem mass spectrometry (TFC-HPLC-MS/MS). Anal Bioanal Chem. 2014;406:793-801.

Saracino MA, lacono C, Somaini L, Gerra G, Ghedini N, Raggi MA. Multi-matrix assay of cortisol, cortisone and corticosterone using a combined MEPS-HPLC procedure. J Pharm Biomed Anal. 2014;88:643-8.

Shimoni A, Azoubel S, Magdassi S. Inkjet printing of flexible high-performance carbon nanotube transparent conductive films by "coffee ring effect". Nanoscale. 2014:6:11084-9.

Smith ZM, Adcock JL, Barnett NW, Francis PS. Chemiluminescence | LiquidPhase $\varkappa^{2}$. In: Worsfold P, Poole C, Townshend A, Miró M, editors. Encyclopedia of Analytical Science (Third Edition). Oxford: Academic Press; 2019.

Sturmer LR, Dodd D, Chao CS, Shi R-Z. Clinical utility of an ultrasensitive late night salivary cortisol assay by tandem mass spectrometry. Steroids. 2018; 129:35-40.

Weltring A, Schaebs FS, Perry SE, Deschner T. Simultaneous measurement of endogenous steroid hormones and their metabolites with LC-MS/MS in faeces of a New World primate species, Cebus capucinus. Physiol Behav. 2012;105:510-21.
West CE, Hardcastle JL, Compton RG. Sono-electroanalytical determination of lead in saliva. Electroanalysis. 2002;14:1470-8.

Wilson R, Schiffrin DJ. Electrochemically oxidized ferrocenes as catalysts for the chemiluminescence oxidation of luminol. J Electroanal Chem. 1998:448:125-30.

Wood P. Salivary steroid assays-research or routine? Ann Clin Biochem. 2009;46: 183-96.

Wright KJ, Oiaidha ZO, Love DP, Aljohani M, Greenway GM, Wadhawan JD. Imaging immunoassay in negative: surface-catalysed chemiluminescence for the detection of pregnancy hormones in artificial saliva. New J Chem. 2018; 42:18641-8.

Yeh C-M, Glöck M, Ryu S. An optimized whole-body cortisol quantification method for assessing stress levels in larval zebrafish. PLoS One. 2013;8:e79406.

Yeh Y-C, Lai G-J, Lin CF, Lin C-W, Sun H-C. How stress influences creativity in game-based situations: analysis of stress hormones, negative emotions, and working memory. Comput Educ. 2015;81:143-53.

Zainol Abidin AS, Rahim RA, Md Arshad MK, Fatin Nabilah MF, Voon CH, Tang TH, Citartan M. Current and potential developments of cortisol aptasensing towards point-of-care diagnostics (POTC). Sensors. 2017;17.

\section{Publisher's Note}

Springer Nature remains neutral with regard to jurisdictional claims in published maps and institutional affiliations.

\section{Submit your manuscript to a SpringerOpen ${ }^{\circ}$ journal and benefit from:}

- Convenient online submission

Rigorous peer review

- Open access: articles freely available online

- High visibility within the field

- Retaining the copyright to your article

Submit your next manuscript at $\boldsymbol{\nabla}$ springeropen.com 